\title{
Anti-PR1/HLA-A2 Monoclonal Antibody Hu8F4
}

National Cancer Institute

\section{Source}

National Cancer Institute. Anti-PR1/HLA-A2 Monoclonal Antibody Hu8F4. NCI Thesaurus. Code C123924.

A T-cell receptor (TCR)-like monoclonal antibody against PR1, a 9 amino-acid (VLQELNVTV) human leukocyte antigen (HLA)-A2-restricted leukemia-associated antigen (LAA) derived from the myeloid leukemia-associated antigens proteinase 3 (P3) and neutrophil elastase (NE), with potential immunostimulating and antineoplastic activities. Upon administration, anti-PR1/HLA-A2 monoclonal antibody Hu8F4 selectively binds to a combined epitope of the PR1/HLA-A2 complex expressed on acute myeloid leukemia (AML) blasts and leukemic stem cells (LSC), and prevents PR1/HLA-A2-mediated signaling. This induces complement-dependent cytotoxicity (CDC), to a lesser extent, antibody-dependent cell-mediated cytotoxicity (ADCC), and CDC/ADCC-independent cytolysis of myeloid leukemia cells. This results in a reduction of cellular proliferation in PR1/HLA-A2-overexpressing leukemic cells. PR1 in combination with the HLA-A2 molecule is highly expressed on AML blasts and LSCS. 